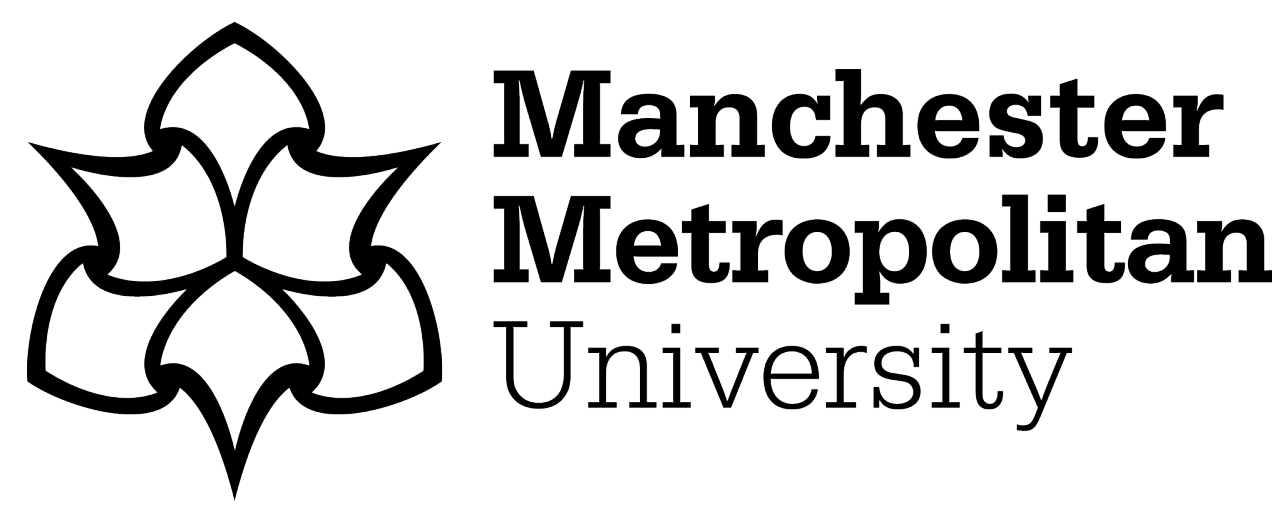

Stone, SH ORCID logoORCID: https://orcid.org/0000-0002-5406-139X and Sanderson, L ORCID logoORCID: https://orcid.org/0000-0003-4772-4973 (2017) Trouble in Happy Valley: The Documentation of a Research Through Design Collaborative Project between a Postgraduate Atelier at the Manchester School of Architecture and the Local Community of a Small Town. In: Proceedings: Architectural Research Addressing Societal Challenges, EAAE ARCC 10th International Conference (EAAE ARCC 2016), 15 June 2016 - 18 June 2016, Lisbon, Portugal.

Downloaded from: https://e-space.mmu.ac.uk/624720/

Publisher: Taylor \& Francis

Please cite the published version 


\title{
The Documentation of a Research Through Design Collaborative Project between a Postgraduate Atelier at the Manchester School of Architecture and the Local Community of a Small Town.
}

\author{
S. Stone \\ Manchester School of Architecture \\ L. Sanderson \\ Manchester School of Architecture
}

\begin{abstract}
Places are defined by the people who live within them. As individuals and communities, deep significance is attached to familiar places, and complex relationships can develop between the residents and the place that they inhabit. This quality is present in the nature of the buildings and the streets, It is often generated by the ordinary actions of local people, many of who believe that their identity is essentially tied to the place that they occupy. This local distinctiveness is characterized by the activities that occur within the specific environment. Thus significant markers are formed, in both the present and in the past, which will allow istepia society to relate to a particular environment. Events that hold value in a community are often manifested in physical form, and therefore allow a population to trace back meanings and connections with their past. This organisation of the past seems to stimulate social cohesion and the feeling of being part of a community, and so, physical links with the past are often important elements within the cohesion of a community.
\end{abstract}

\section{INTRODUCTION}

Neighbourhood planning is a highly controversial policy. It was part of the Localism Bill introduced by the British Government in 2011. The policy shifted the responsibility for the decisions about the size, shape and location of neighbourhood development from central to local government. Communities are now asked to decide upon the nature and character of their particular district and actively participate in decisions about future developments. In theory this should be a positive move and quite straightforward; the UK has a housing shortage and rather than a topdown imposition of new properties, the bill allows local people to decide upon their own development strategy. However, well-meaning residents who have little or no training in planning, or skills in urban and rural development are making decisions too quickly without sufficient consultation or knowledge. This means that residential developers have been able to buy up packages of land and develop areas of the greenbelt and other bits of countryside that had so far been unavailable to them. More appropriate brownfield sites are often overlooked in the need to act swiftly and decisively and developments are not always the ones that the community really needs.

Bollington, known locally as Happy Valley, is a small post-industrial town in Cheshire in the North West of England, just within commuter distance of Manchester. It is a town defined by its topography; with heroic remnants of the Industrial Revolution such as the canal and the railway, contrasting with a calmer and more picturesque local vernacular of cottage, terraces, garrets and greens. Despite the remnants and detritus of warehouses and factories, it is an attractive and desirable place to live. The town council has already approved a number of substantial new-home developments, despite the fact that their Neighbourhood Plan is not yet in place, indeed, the discussion has hardly even started.

Continuity in Architecture is a postgraduate atelier, which has been established at the Manchester School of Architecture for more than 20 years. The atelier runs programmes for the design of new buildings and public spaces within the existing urban environment. The emphasis is on the importance of place and the idea that design of architecture can be influenced by the experience and analysis of particular situations. This interpretation of place can provide a contemporary layer of built meaning within the continuity of the evolving town or city.

The Bollington Neighbourhood Planning committee approached Continuity in Architecture to jointly develop a plan for the town that would sustain the place for the foreseeable future, that would allow the town to grow without losing its inherent character and would facilitate a future for all of the residents, not just those who can afford to live there. This partnership will develop a masterplan for Bollington, it will identify areas that appropriate development can take place, propose designs for new buildings, suggest the redevelopment of existing structures and recommend areas for public space. 


\section{COMMUNITY}

One of the fundamental characteristics of our postmodern society is democratic modernism and the rise of individualism. A new form of interconnectedness has arisen, one which bypasses normal state control and therefore operates despite of, rather than because of existing regulations. Advances in communications, information and transport technologies have facilitated a revolution in the global flow of objects, information and people. This has led to a pluralism of world-view, expansion of individual choice and a liberation of lifestyle (Gallent and Robinson, 2013: 10). This suggests that the global diffusion of culture and identity is incompatible with the traditional structures of the post-war period, which has inevitably led to a more diverse and separated patterns of sociability. This has prompted a questioning of traditional forms of authority, and conventional ideas of citizenship, social contact and allegiance.

A consequence of this individualism is a substantial rise in the number of community and interest groups, each with their own agendas and priorities. Traditional government, in which policy is formed by experts and administered by state officials, is increasingly being challenged. Within the UK, this movement was recognised as early as the beginning of the 1980s, when the rightwing Conservative administration led by Margaret Thatcher sought to confine the role of central government to strategic direction, while public policy formation and implementation were delegated to autonomous agencies. Since then, this policy of reform that challenges the basic principle of top-down governance, and promotes the devolution of responsibility for decision making away from the centre, has been a key aspect of all UK governments, including the Leftwing (New) Labour government, middle ground Conservative-Liberal Coalition and the rightwing Conservative only administration. (It should be noted that this policy of devolution is not only restricted to the UK, it is an international movement, but this paper is particularly focussed upon the UK and will therefore not discuss the international aspects of devolution).

Over the last generation the structures of community representation have been actively promoted through a series of Local Government Acts, which advanced community representation, especially that of parish councils. National housing delivery targets had been set and the advocacy of the "small state" at the beginning of the second decade of the twentyfirst century paved the way for the formation of Localism. The intention of the Localism agenda is to empower local people to control developments within their own neighbourhood. That is, for (unpaid) community groups to work with local government and trained planners upon a strategic plan for their immediate neighbourhood. The existing planning system helps decide what gets built, and where and when it happens, it is essential for supporting economic growth, improving people's quality of life, and protecting the natural environment. The purpose of the Localism Bill is to formulate effective planning, widen ownership of the process, create a broad agreement around development decisions, and ensure the avoidance or prevention of major conflict. The National Planning Policy Framework for England describe the Neighbourhood Plan thus:

"Neighbourhood planning gives communities direct power to develop a shared vision for their neighbourhood and shape the development and growth of their local area. They are able to choose where they want new homes, shops and offices to be built, have their say on what those new buildings should look like and what infrastructure should be provided, and grant planning permission for the new buildings they want to see go ahead." (National Planning Policy, 2012: Online).

The Localism Act 2011, along with associated regulations, lays out all the processes for preparing and putting in place neighbourhood planning tools. This includes three separate tools; Neighbourhood Development Plans (NDPs), Neighbourhood Development Orders (NDOs) and Community Right to Build Orders. Neighbourhood Development Plans are policy documents (like local plans), which could include policies on where and what kind of development will be allowed in the parish or neighbourhood area. Neighbourhood Development Orders can grant planning permission for a particular type of development, for example housing, on a particular site. Community Right to Build Orders are a special type of Neighbourhood Development Order.

The Neighbourhood Plan is formulated by a number of different groups; each with their own different interests and concerns, but who have come together to forge a new future for their own immediate locality. The intention is to put power in the hands of local residents, employees and business, councils and civic leaders; that is those who know best the needs of their local areas. Neighbourhood planning is optional, not compulsory, and importantly the members are not elected; anyone who lives or works in the in the area can join, simply by turning up, although there is a minimum of 21 members. The community groups are generally self-selected, made up of interested and concerned individuals who genuinely feel that they need to protect or that they can make a contribution to a plan for their neighbourhood.

Neighbourhood planning is occasionally referred to a community-based planning, and although it may be a better description of the process, it is not generally used. Various community groups working together may develop the plan as a shared activity, however it is the location of the activity at a particu- 
lar geographical scale that defines the title, however uncertain the actual parameters of the neighbourhood are.

There are strict guidelines for how the Neighbourhood planning forum must operate. These were laid out in: Neighbourhood Plans, a Blueprint for Devolution and Local Democracy (Jellinek, 2014: Online) as follows:

1. Each forum picks its own members, sets its own area and writes its own constitution. Membership has to represent the character of the area, for example, balancing business and resident representation and geographical spread.

2. The forum will engage with the local community, assemble relevant evidence and write a development plan.

3. The development plan must: align with European, national and local policy, it must plan for sustainable development, and importantly, it must not be excessively static

4. A national programme offers support from consultants such as highway engineers, health experts and planning officials who can help translate intentions into policy.

Neighbourhood Planning certainly enables communities to play a much stronger role in shaping the areas in which they live and work and in supporting new development proposals. It provides an opportunity for communities to set out a positive vision for how they want their community to develop over the next ten, fifteen, twenty years in ways that meet identified local need and make sense for local people. To encourage the community to engage with the project, they will receive $25 \%$ of the revenues from the Community Infrastructure Levy arising from the development that takes place in their area, and the use of these funds should reflect the priorities which were formally set out in the neighbourhood plan.

Of course there are many potential problems with this system and at every stage of the process. Untrained but enthusiastic people who want something specific, which may or may not benefit the whole community could be seen as a recipe for disaster, or it could be that they are so perfectly positioned to understand exactly what the needs of the neighbourhood are that a genuinely productive and responsive solution is created.

Problems that could occur and complex and unprecedented. Will sufficient local people actually engage with the project? The group may not agree upon a unified approach, or more than one group will emerge, each putting forward a proposal for a particular area. Somewhat self-interested business people could group together to bring forward some schemes for commercial development which may give rise to objections from residential occupiers of that part of the neighbourhood. Once the consultations with locals and with experts have taken place, and the proposals for the development of the neighbourhood developed, the plans still could be rejected, for instance, in Slaugham in Sussex, it was deemed not to have taken sufficient account of EU environmental rules, and had insufficient evidence that its housing targets could be met.

In legislative terms, Neighbourhood Planning is still in its infancy. There is very little research into its effectiveness and pitfalls are not being well evidenced, documented or mitigated against. Most importantly perhaps, there is a limited supply of assistance available. Funds $(£ 50 \mathrm{~m})$ have been made accessible by the government for local planning authorities to help local groups through the process, but what happens when this is all gone? The local council may reject the proposals created by the group outright, would this undermine the whole process and of course, the biggest concern for any architect, planner or designer is how can such decisions about the future of the built environment be devolved to people with no training and possibly no aptitude for it?

\section{CONTEXT}

The Industrial Revolution established Bollington as one of the most prominent cotton manufacturing communities in the north of England. Until the late $18^{\text {th }}$ century, the town activities were broadly rural with a focus on sheep farming, wood cutting, stone cutting and surface coal mining. However, the town was ideally positioned to become an important actor in the rapid industrial development that spread across the north-west of England. The town grew fast and was dramatically altered, beginning in about 1760 with the construction of the first of a series of cotton mills. These were powered by the River Dean and located at the lowest parts of the town.

"Once someone decided to build a mill there was a need for stone with which to construct it, so quarries were opened up. Mills and quarries needed labour so cottages were built and roads laid out. Homes needed warmth so coal mining developed. All of these facets of urbanisation required trade skills - shopkeepers, butchers, brewers, publicans, liverymen, farriers, carters, churchmen, cordwainers, cloggers, dressmakers, hatters, and so on. Very soon an entirely urban community was developed being provisioned by the surrounding rural community." (Bollington Civic Society History Group, 2015: Online)

Advances in industrialisation meant that the river soon proved to be insufficient, and therefore in 1831 a canal was constructed in an elevated position above the expanding town. This necessitated the construction of a number of stone aqueducts which 
served the larger coal powered mills. This split topography of a town generated by the river and then above that the high level canal is one of the distinguishing features of Bollington; the drama of which was further enhanced in 1870 by the introduction of the Macclesfield, Bollington and Marple Railway. This runs from south to north on a series of high level viaducts.

Workers lived below this massive infrastructure in stone terraces often built with shared yard spaces to the rear. The mill owners and middle classes occupied larger cottages and semi detached stone houses. Houses were modest but well built, benefitting from the close proximity of a number of quarries, mining Kerridge Stone from the nearby area.

In a story common to most of the Western World, in the 1950's the town began a long slow decline; the textile industry faded, work and commercial activity dwindled and the rise of private transport and out of town shopping centres attracted residents to other areas (Bollington Civic Society History Group, 2015: Online). The Beeching Cuts of 1963 which saw a notable reduction in rail provision in Great Britain, caused the closure of the Bollington railway in 1971, just 101 years after its arrival. Sometime later this high level viaduct was transformed into a recreational path, now called the Middlewood Way. The mill buildings slowly closed and although the majority are still empty, some were demolished and a few have been converted for such uses as apartments, independent retail and a gym.

The aqueduct is man's design

A tower of strength to Bollington

A Herculean labour

Completed eighteen thirty one

The advent of the speedy train

Soon replaced the silent waters

Whose short life was terminated

Like a lamb led to the slaughter

(The Aqueduct 1831. Broster, 1973: 45)

The rapid expansion of the town caused it to grow in an unnatural manner, it contains no distinct centre and the axial road effectively divides the town in two. However, despite this uncomfortable urban organisation and the remnants and detritus of warehouses and factories, Bollington in the present day is seen as an attractive and desirable place to live. With this in mind, housing is almost certainly the biggest challenge to be faced by Bollington and as such has been the driving force behind the development of a Neighbourhood Plan.

\section{CONTINUITY}

The college of Continuity in Architecture (CiA) at the Manchester School of Architecture was established in 1994. It is a post-graduate studio for teaching and research. The attitude that $\mathrm{CiA}$ take towards architecture has its roots in Contextualism. This is an approach to the design of the urban environment that uses the process of analysing and understanding the nature and the qualities of place to develop new elements. CiA believe that it is the responsibility of the architect to work with the identity of a place, to create architecture that is appropriate to its location and does not destroy the character of an area.

Contextualism emerged as a reaction to Modernism and now, more than a generation old, $t$ it is more relevant than ever. Our post-modern society has the need to embrace ideas of memory and experience and this means that Contextualism is at the forefront of theories about contemporary architecture, urban design and interior design. The use and re-use of an architectural site creates a direct connection with the past. It is a strategy that establishes an explicit relationship with history, not just with the site, the building and its immediate surroundings, but also with the society that constructed it. The reading of a building or site can uncover a layered and stratified narrative and the understanding of the inherent qualities and conditions of building or site can provide clues to the redesign of the place. It is through a thorough knowledge and understanding of the existing condition that the architect or designer can uncover the meaning within a place. This knowledge can be used to activate, liberate and instigate a new future for the building. And so the architect or designer who is to develop a new strategy for an urban environment, or design a collection of new structures or even modify, transform or change an existing building to accommodate a new use has to adhere not just of the agenda of the new users, but also the intentions of the original place. This act of modification is part of the evolution of the site, it as another layer in the archaeology of the situation.

For over twenty years, $\mathrm{CiA}$ has been promoting a particular approach to the development of architectural solutions, one with profound integrity and which is contextual, expressive, and environmentally appropriate. Modesty and cooperation are emphasised and as such, the atelier encourages a response that does not generate a gratuitously flamboyant or overtly icon-centric solution or attitude, but instead advocates an approach that embraces a close and sensitive contextual reading of place. Building during any period of history represents a significant commitment of human, material and financial resources. The most successful cities have adapted urban patterns and buildings to uses never imagined by their original creators. CiA are inspired by the efforts of architects working within existing structures and urban fabric to produce a responsive architecture of narrative, space, intervention, and detail. Through both theories and the example of architects engaged in critical practice, the aim is to show that the ideas and methods examined within the postgraduate studio have real applications. 


\section{COLLABORATION}

In November 2014 Cheshire East Council agreed to support the production of a Neighbourhood Plan for Bollington thus providing the local community with more control over the future developments in the town. Headed up by Professor Michael Burdekin and Councillor Amanda Stott, the decision came in the wake of the National Housing Crisis with a series of houses allocated to each area of the UK. The committee included key residents: retired Conservation Officer Sandra Edwards, Councillor Ken Edwards and Town Clerk David Naylor.

A few months after the committee formed, recently qualified Architect and CiA Alumni, Peter Millburn-Brown moved to the area and saw an opportunity to connect the process to architectural education, linking back to similar contextualised projects undertaken in his own postgraduate studies. This partnership were tasked with the development of a masterplan for Bollington, the identification of areas of appropriate development, propositions for new buildings, suggestions for the redevelopment of existing structures, and recommendations for areas of public space.

Over recent years the population in Bollington has been steadily rising (Bollington Civic Society History Group, 2015: Online) which created the need for a number of new developments in the area which have, to date, been designed in a disconnected and haphazard fashion without a wider plan of the area being considered. The loss of the mills and other large industrial buildings has provided the town with a number of notable building plots which have been bought by housing developers (e.g. Bellway Homes). These have been somewhat unsympathetically developed as semi detached family homes.

Interestingly there is some controversy around the number of new houses which have been designated to be constructed the local area; Cheshire East Council have stipulated a quota of 300 new houses (within the UK there is insufficient housing, and each local authority is tasked with making a contribution towards the 240,000 new houses per-year target set out by the 2007 Labour government). Since 2010 there have been 172 houses constructed in Bollington, including the 86 located in Clarence Mill, but it is unknown whether these are included within the original quota. A further 48 houses are awaiting Planning Approval, thus it appears that there is a shortfall of 80 units. However, no further clarification has been offered as to the date when the 300 houses were designated so the exact number, somewhere between 80 and 300, is unknown.

Numbers aside, there is an inherent question of type. Affordable housing is certainly a priority for Bollington, this will allow families to grow without having to move from the local area. Building houses affordably is a challenge to any potential developer on the complicated brownfield sites that are availa- ble, with drastic topography, flood risk zones, listed structures and conservation areas. Solutions need to be well considered and thoughtful to their surroundings. Conventional solutions of "cookie cutter housing" may not be the answer.

Until recently Bollington did not attract commuters - it does not have a train station and the journey by car is just too long to be comfortable, but this is changing as house prices in other areas rise. With this in mind it is very much a self-sustaining town with residents who are proactive and passionate about their home. Apart from the approval of two substantial housing developments in 2014, the majority of planning applications in recent years have been met with overwhelming numbers of objections.

However, the town cannot remain frozen as the demands for additional housing will cause an inevitable rise in population; new homes will be required, as possibly will new schools, shops, workplaces and recreational space.

To be successful, the Neighbourhood Plan for Bollington would need to address not only the parcels of land available for development but the type, design, layout and quality of the buildings themselves. One of the biggest difficulties is developing a plan which can act as a design guide without restricting the opportunities for the more unique or perhaps even heroic developments which have come to define the town.

The inclusion of live agendas, such as this one, within architectural education have been increasing in popularity in recent years and this is in contrast with the tendency since the early part of the twentieth century for architectural education to be 'product' orientated most commonly concerning a traditional design brief to create a given building on a given site (Bishop. 1997: 87). This adjustment reflects the changing nature of the profession. One of the key advantages of this Problem Based Leaning (PBL) approach is the development of employability and life long learning skills which begin to set the context for a lifetime of continued professional development both formal and informal. The job of an architect requires both architectural design skills alongside the ability to analyse, organise, collaborate and communicate ideas; that is to solve problems. Within architectural education there has been a inclination to create a simulated setting which allows a students to show off the full range of drafting and design skills but not necessarily the additional skills required to deal with a real life problem.

"Much design education is very remote and esoteric and even where design work has a 'real life' context there is a tendency to 'tailor' the design brief, often for valid educational reasons, in order that the creativity of the student is not limited by the reality of the context of the design problem." (Bishop, 1997: 87). 
CiA was determined that the students would have the opportunity to react to the live context of the Neighbourhood Plan, while also taking into consideration the wider context of the town. This had advantages to both the atelier and the committee. The atelier could look at the problem outside of the restrictive framework set by national legislation and test ideas more freely, meeting wider curricular objectives but also bringing a new way of looking at the situation. Experience has shown that Neighbourhood Planning is a lengthy process requiring a number of layers of consultation, while the committee were bound by these timeframes, the atelier could be more responsive and also more creative, using drawings, models and interventions to investigate the area in a different way.

Work began in September 2015, and the academic-year-long studio project was broadly split into four parts: Interrogating, Intervening, Planning and Realisation. Each project resulted in outputs that were exhibited in Bollington.

'Interrogating' saw the production of a book which collected together initial research and subsequent analysis of Bollington. The cohort of students were divided into overlapping groups and each were to examine something specific; Town Evolution (historic maps, historic narrative, key figures), Buildings (typology studies, elevation studies, key building analysis), Topography (site sections, site models), and Geography (climate, population, flora, occupation, activities). When all information was collected, the groups saw patterns emerging and split all research into two distinct categories: Heroic Remnants (Geology, Mills, River, Canal, Railway, Cotton, White Nancy) and Slow Vernacular (Houses, Doors, Windows, Churches, Persistence, Growth, Population, Territories, Townscape). After a series of weeks a book emerged: Oddments and Epigrams: An Intimate Interrogation of Bollington.

The second project asked the students to create a temporary solution to a site-specific problem in Bollington. Misselwitz, Oswalt and Overmeyer, who looked specifically at ephemeral projects in Belin developed 'two main hypotheses: 1 - spontaneous, temporary uses can have positive long term effects; and 2 - the unplanned phenomena of temporary uses can be successfully incorporated into the planning and management of cities.' (2013: 273). In collaboration with the local community, students worked on six proposals for interventions which were then either built, modelled or tested in the town.

Each proposition was designed to connect to the earlier research of Bollington and acted as a method of engaging with the local community in the wider objectives of the Neighbourhood Plan. The ideas were diverse and bold; one student used mirrors to reflect the heroic elements of the town back to the everyday lives of its residents, another explored materiality by casting and installing a concave golden stone, a third student used light to redefine the ruin of Ingersley Vale Mill. Others used techniques local to the area, one creating a kinetic machine driven by the River Dean, and another using the process of engraving on velvet called devore to create a panel imprinted with the elevation of the Clarence Mill. Finally, there was a project to reinstate the interior lining of the monument White Nancy into an end terrace house. All ideas were collated in an exhibition in Bollington Arts Centre in January 2016 where the local community began to discuss and comment more broadly on the way they saw the town develop.

This was a precursor to a much more serious project entitled 'Planning'. The students worked with an urban planning specialist from Think Place and through a series of design workshops built upon the knowledge of the town and developed a series of strengths, weaknesses, opportunities and threats for six key areas of the town. These were: Movement, History and Heritage, Townscape, Sport and Culture, Landscape and Economy.

"Designers don't create communities. Design, however, if done badly can fragment communities and isolate people. If done well, it can bring people together, allow neighbours to bump in to each other, children to play safely and for the gradual shaping of a place over time by its people." (Think Place, 2006: Online)

A proposal for the town was developed which highlighted a number of potential sites in Bollington. Looking beyond these sites as pockets of empty space, the workshop aimed to determine buildings, structures and landscapes which had the opportunity for development as well as traditionally conceived development plots. Working momentarily outside of the Neighbourhood Planning Legislation allowed students to make big marks in the town, to undo previous developments and consider the ideal situation. Through dialogue with the local community this plan will evolve further, it will question how the town might develop in the near future and what type of developments should be sought.

As the project reaches its final stage, the atelier is working in three groups on the 'Realisation' phase of works, one highlighting the Civic Centre of Bollington, one focussing on the Recreational Centre of Bollington and one looking at the Industrial Centre of Bollington. Each group are tasked with developing a series of sites to be used for a mixture of community, commercial and residential uses. A minimum of 80 houses are to designed across the town as part of the process, these will be supported with a series of car parking spaces in line with the objectives of the overarching Neighbourhood Plan. The buildings are to be presented in a further exhibition in Bollington in May 2016 alongside the Policy Docu- 
mentation for the Neighbourhood Plan. This joint exhibition aims to provide residents with a collective vision for the future of the town.

\section{CONCLUSION}

"Obviously some middle ground is needed. To retreat to a hopelessly artificial past is unrealistic, but to allow a brutalizing system to dominate and destroy traditional urbanism is irresponsible." (Schumacher, 1971: 79)

Places are defined by the people who live within them. As they grow and change to meet the new demands of the community that inhabits them, layers of meaning and memory must be 're-read, reanalysed, and re-worked' (Boyer, 1996: 322).

Neighbourhood Planning will continue to create controversy at both a local and a national level as the power to decide upon the future of places is transferred to the local community. This devolution has the very positive potential to engage local people in the decisions that are made about their homes, as they are the ones who know the location the best and they are the ones who will have to live with the consequences of any decisions made. However, this also has the danger of opening up large parcels of land to profit hungry developers in a bid meet the target number of new homes set by national government. Commercial players on Neighbourhood Planning Committees often outnumber well-meaning residents, who with little or no training in planning, or skills in urban and rural development are at risk of making decisions too quickly without sufficient consultation or knowledge.

In Bollington, by thinking collaboratively, this project has helped empower local people to contribute towards the future of their own town. It has provided the settlement with a plan that is suited to their needs, because it is based upon a thorough examination of the place itself. The analysis and understanding of the existing situation plus the identification of suitable areas for development combined with the design of proposals for new buildings, all of which was generated by the by the students has provided the community of the town with the knowledge to act in an emboldened and informed manner.

Through engagement with the over arching curriculum within architectural education, the project bought together local residents and students from the Manchester School of Architecture with mutual benefit to both the future of the small town of Bollington and the educational objectives of the atelier Continuity in Architecture. It is in this context that the student becomes aware of their role in the "public understanding of the process of design and construction which requires the student to step outside the protected environment of the school of architecture and communicate both orally and visually, in the context of peoples lives' (Bishop, 1997: 87).
The Neighbourhood Plan Collaboration for Bollington will be completed this academic year and will be documented in the production of a final plan and series of notional building designs. This project takes the Neighbourhood Plan beyond what is normally expected. The general public have been able to comment on ideas because they have been visualised through the generation of real proposals depicted by drawings and models, are therefore easily accessible. An exhibition scheduled for May 2016 and a series of public meetings will advance the dialogue and engagement, which will further enhance the plan for Bollington, this will hopefully provoke great discussion within the town. Although these buildings are entirely hypothetical at this stage, they open up a conversation with the local community about the type of architecture that might be fitting for Bollington. It will be an architecture based upon an informed opinion of the place. The project should be viewed as an example of best practice in Neighbourhood Planning and will disseminated further at both a local and national level.

\section{REFERENCES}

Bishop, J. (1997). The Architecture in the City Project. Unpublished.

Bishop, P. and Williams, L. (2012). The Temporary City. London: Routledge.

Bollington Civic Society Group, (2015). Bollington, Cheshire $U K$. [online] Available at: http://www.happy-valley.org.uk [Accessed 18 Feb. 2016].

Boyer, M. (1996). The City of Collective Memory. Cambridge, Mass.: MIT Press.

Deon, L., Caruso, A. and Saint John, P. (2002). Knitting, Weaving, Wrapping, Pressing ; Stricken, Weben, Einhüllen, Prägen - Caruso St. John Architects. Basel: Birkhäuser.

Frampton, K. (2007). Modern Architecture. London: Thames \& Hudson.

Gallent, N. and Robinson, S. (2012). Neighbourhood Planning. Bristol: Policy Press.

Gov.uk, (2012). National Planning Policy Framework. [online] Available at: https://www.gov.uk/government/publications [Accessed 18 Feb. 2016].

Jellinek, D (2014). Neighbourhood Plans, a Blueprint for Devolution \& Local Democracy. [online] Available at: http://www.theinformationdaily.com/2014/11/03/devolutio n-pointers-in-radical-neighbourhood-plans [Accessed 18 Feb. 2016].

Marot, S. (2003). Sub-urbanism and the Art of Memory. London: Architectural Association.

Oswalt, P., Overmeyer, K. and Misselwitz, P. (2013). Urban Catalyst. Berlin: Dom Pub.

Rowe, C. and Koetter, F. (1983). Collage City. Cambridge, Mass.: MIT Press.

Schumacher, T. (1971). Contexualism: Urban Ideals and Deformations. Casabella 359-360.

Silvetti, J. (1992). Interactive Realms. Cambridge, MA: Harvard University Graduate School of Design.

Think Place, (2016). About. [online] Available at: http://www.think-place.co.uk [Accessed 18 Feb. 2016]. 